\title{
In Vivo 3-D Vector Velocity Estimation with Continuous Data
}

Holbek, Simon; Pihl, Michael Johannes; Ewertsen, Caroline; Bachmann Nielsen, Michael; Jensen, Jørgen Arendt

\section{Published in:}

Proceedings of IEEE International Ultrasonics Symposium

Link to article, DOI:

10.1109/ULTSYM.2015.0235

Publication date:

2015

Document Version

Peer reviewed version

Link back to DTU Orbit

Citation (APA):

Holbek, S., Pihl, M. J., Ewertsen, C., Bachmann Nielsen, M., \& Jensen, J. A. (2015). In Vivo 3-D Vector Velocity Estimation with Continuous Data. In Proceedings of IEEE International Ultrasonics Symposium IEEE. https://doi.org/10.1109/ULTSYM.2015.0235

\section{General rights}

Copyright and moral rights for the publications made accessible in the public portal are retained by the authors and/or other copyright owners and it is a condition of accessing publications that users recognise and abide by the legal requirements associated with these rights.

- Users may download and print one copy of any publication from the public portal for the purpose of private study or research.

- You may not further distribute the material or use it for any profit-making activity or commercial gain

- You may freely distribute the URL identifying the publication in the public portal 


\title{
In Vivo 3-D Vector Velocity Estimation with Continuous Data
}

\author{
Simon Holbek*, Michael Johannes Pihl*, Caroline Ewertsen ${ }^{\dagger}$, Michael Bachmann Nielsen ${ }^{\dagger}$ and Jørgen Arendt Jensen* \\ * Center for Fast Ultrasound Imaging, Dept. of Elec. Eng., Bldg. 349, Technical University of Denmark, \\ 2800 Kgs. Lyngby, Denmark \\ $\dagger$ Department of Radiology, Copenhagen University Hospital, \\ 2100 Copenhagen, Denmark
}

\begin{abstract}
In this study, a method for estimating 3-D vector velocities at very high frame rate using continuous data acquisition is presented. An emission sequence was designed to acquire real-time continuous data in one plane. The transverse oscillation (TO) method was used to estimate 3 -D vector flow in a carotid flow phantom and in vivo in the common carotid artery of a healthy 27-year old female. Based on the out-of-plane velocity component during four periodic cycles, estimated flow rates in an experimental setup was $2.96 \mathrm{ml} / \mathrm{s} \pm 0.35 \mathrm{ml} / \mathrm{s}$ compared to the expected $3.06 \mathrm{ml} / \mathrm{s} \pm 0.09 \mathrm{ml} / \mathrm{s}$. In the in vivo measurements, three heart cycles acquired at $2.1 \mathrm{kHz}$ showed peak out-of-plane velocities of $83 \mathrm{~cm} / \mathrm{s}, 87 \mathrm{~cm} / \mathrm{s}$ and $90 \mathrm{~cm} / \mathrm{s}$ in agreement with the 92 $\mathrm{cm} / \mathrm{s}$ found with spectral Doppler. Mean flow rate was estimated to $257 \mathrm{ml} / \mathrm{min}$. The results demonstrate that accurate real-time 3$D$ vector velocities can be obtained using the TO method, which can be used to improve operator-independece when examining blood flow in vivo, thereby increasing accuracy and consistency.
\end{abstract}

\section{INTRODUCTION}

The cardiovascular blood flow is very complex as it propagates in all three dimension, where short lived vortices can can arise and vanish within $100-200 \mathrm{~ms}$ [1]. So, to provide the true dynamics of the blood flow, 3-D vector velocities at a high frame rate is therefore necessary. However, current methods for velocity estimations are mainly restricted to $1-\mathrm{D}$ or $2-\mathrm{D}$ methods.

For estimating 2-D vector flow various methods have been proposed, e.g., speckle tracking [2], directional beamforming [3], plane wave emissions as suggested in [4] and transverse oscillation (TO) [5]. 2-D vector flow gives a more realistic picture of the actual flow, but does not provide information about the out-of-plane velocity component.

For realtime out-of-plane velocity estimation, a 2-D transducer is needed. A 2-D piezoelectric transducer was used in previous work, which showed that all three velocity components can be obtained for two crossing planes [6] using a 3-D implementation of the TO method [7] [8] and Provost et al with a similar transducer, estimated the axial velocities in a full volume using Doppler techniques [9].

One method to increase the frame rate significant, is by designing an emission sequence for continuous data acquisition. Continuous data acquisition offers several interesting options; for instance, the frame rates for velocity estimates can be increased to the $\mathrm{kH}$ range, which helps to capture complex flow patterns. Second, adaptive velocity estimation algorithms can be applied to create a more complex and dynamic echo cancelling or increase the detectable velocity range under the rapid changing conditions during a cardiac cycle.

This paper presents the results from 3-D vector velocity estimation using continuous data in both an experimental setup and for an in vivo measurement. The out-of-plane velocity components is in both cases used to derive the flow rates. With the applied emissions sequence, ultrafast frame rates up to 2.1 $\mathrm{kHz}$ was obtained. In combination with the TO method, both slow flow in the end-diastole and fast flow in the peak-systole could be detected.

\section{Materials \& Methods}

This section describes the continuous 3-D method. It introduces the equipment, emission sequence, data processing, and theoretical properties of the TO velocity estimator. The basic principles of the TO method is described in [5][10].

\section{A. Emission sequence}

In Fig. 1 an illustration is seen of how the applied sequence was designed to yield continuous data. The idea is that the duration between emissions of two identical flow lines $F_{i}$ should be the same at all times. This could for instance be achieved by emitting the flow lines $F_{1}-F_{5}$ consecutively, followed by emitting the B-mode line $B_{1}$. Next, the flow lines $F_{1-5}$ would be emitted again, followed by the B-mode line $B_{2}$ etc. When the desired amount of B-mode lines $B_{n}$ has been reached, the sequence repeats itself from the beginning. The number of unique B-mode emission $B_{N}$ was set to 64 in all measurements. A schematic representation of an emission sequence is

$$
\begin{gathered}
F_{1} \rightarrow F_{2} \rightarrow F_{3} \rightarrow F_{4} \rightarrow F_{5} \rightarrow B_{1} \rightarrow \\
F_{1} \rightarrow F_{2} \rightarrow F_{3} \rightarrow F_{4} \rightarrow F_{5} \rightarrow B_{2} \rightarrow \\
\vdots \quad \vdots \quad \vdots \quad \vdots \quad \vdots \quad \vdots \\
F_{1} \rightarrow F_{2} \rightarrow F_{3} \rightarrow F_{4} \rightarrow F_{5} \rightarrow B_{N} \rightarrow
\end{gathered}
$$

This would produce continuous flow data and one or multiple continuous B-modes images if desired. 


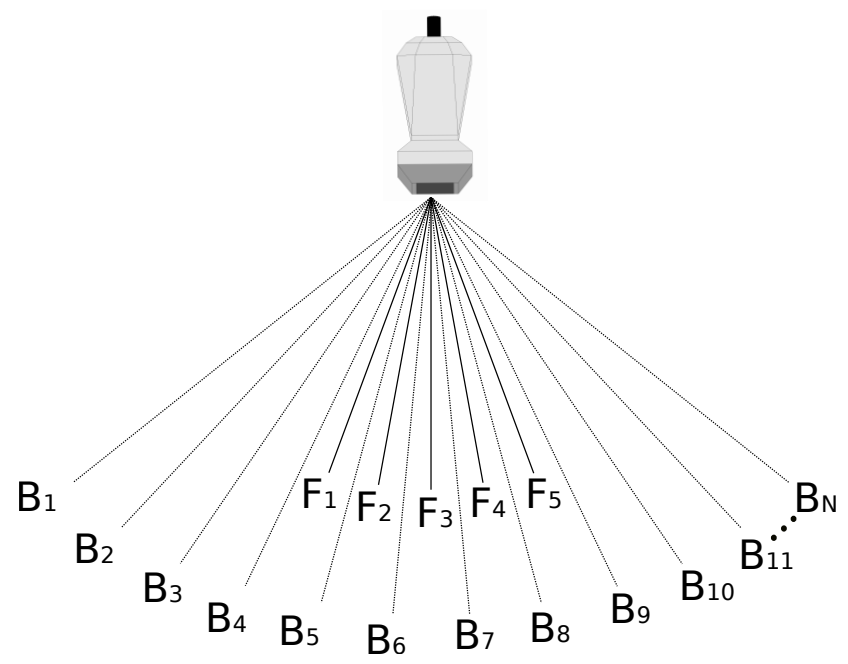

Fig. 1. Illustration of how an emission sequence for continuous data acquisition could be constructed. First, the flow lines from $F_{1}$ to $F_{5}$ are emitted followed by a B-mode line $\mathrm{B}_{1}$. The next cycle contains again all the flow lines from $F_{1}$ to $F_{5}$ and is ended with the $\mathrm{B}$-mode line $\mathrm{B}_{2}$. This continues until $\mathrm{B}_{N}$ is reached, and the first cycle can be repeated again. The angles spanned are only for illustrative purpose and not to scale.

\section{B. Velocity estimators}

The axial velocity estimates were based on the autocorrelation approach [15], and the two transverse velocity components were found by using the TO method [5][10].

For each transverse velocity estimate two TO beams were beamformed along the lines separated spatially by their respective transverse wavelengths $\lambda_{x} / 4$ or $\lambda_{y} / 4$, thereby generating two fields phase-shifted by $90^{\circ}$. The two transverse wavelengths are theoretically given by

$$
\begin{aligned}
& \lambda_{x}(z)=2 \lambda_{z} \frac{z}{d_{x}} \\
& \lambda_{y}(z)=2 \lambda_{z} \frac{z}{d_{y}}
\end{aligned}
$$

where $\lambda_{z}$ is the wavelength of the emitted pulse, $z$ is the axial depth of the beamformed RF-line and $d_{x}, d_{y}$ are the distances between the two peaks in the receive apodization in the $x$ and $y$-direction. The apodization used in receive was in both directions two rect profiles spanning 8 elements with a spacing of 16 elements between. From [10], the maximum transverse velocities that could be estimated without reaching the aliasing limit were

$$
\begin{aligned}
& v_{x_{\max }}=\frac{\lambda_{x}}{4 k} f_{p r f} \\
& v_{y_{\max }}=\frac{\lambda_{y}}{4 k} f_{p r f},
\end{aligned}
$$

where $k$ is the lag used in the autocorrelation and $f_{p r f}$, is the effective pulse repetition frequency between two emissons of the same flow line.

\section{Measurement setup}

The experimental ultrasound scanner SARUS [11] with 1024 channels in receive and transmit was used along with a Vermon $3.5 \mathrm{MHz}, 0.3 \mathrm{~mm}$ pitch, $0.278 \mathrm{~mm}$ height $32 \times 32$ element 2-D phased array transducer (Vermon S.A., Tours, France) for data acquisition. See Table I for transducer specifications. The emitted frequency was $3.0 \mathrm{MHz}$, to avoid gratinglobes and reduce transducer heating. Data was sampled from all 1024 channels and stored for offline processing on a Linux cluster.

The employed 2-D matrix probe contains, due to construction issues, three inactive rows in the $x$-direction. The dimensions of the actual transducer is therefore $35 \times 32$ with the active aperture being $32 \times 32$.

\section{Setup for flow pump measurements}

For the phantom measurements a predefined pulsating carotid flow profile was generated with a flow pump (CompuFlow 1000 System, Shelley Medical Imaging Technologies, Ontario, Canada) containing blood mimicking fluid with backscattering coefficient equivalent to blood cells. With the included software CompuFlow 1000 System, a carotid flow profile was generated with a cycle time of $0.84 \mathrm{~s}$ and a flow rate of $3.06 \mathrm{ml} / \mathrm{s} \pm 0.09 \mathrm{ml} / \mathrm{s}$. A blood mimicking fluid was pumped through a carotid phantom (Danish Phantom Design, Frederikssund, Denmark) with a diameter of $0.8 \mathrm{~cm}$ located at a depth of $2.7 \mathrm{~cm}$. Properties for the sequence used for the experimental setup can be seen in Table I.

\section{E. Clinical setup}

Intensity measurements to ensure compliance with the FDA limits, were performed for the in vivo sequence. The derated mechanical index (MI) was 1.29 and the pulse repetition frequency $f_{p r f}$ was scaled to $12.6 \mathrm{kHz}$ to obtain $I_{\text {spta. } 3}=$ $720 \mathrm{~mW} / \mathrm{cm}^{2}$ in accordance with FDA limits. The in vivo measurement was performed on a healthy 27-year old female who had been resting for 15 minutes before measurements were conducted to ensure a steady flow. The scans were performed by an experienced radiologist. Properties for the in vivo sequence are summarized in Table I as well.

\section{DATA PROCESSING}

The stored data was processed offline. The raw RF data was match filtered and Hilbert transformed before the IQ data was beamformed with the Beamformation Toolbox 3 [12]. In this part, the three velocity components were decoupled, such that one line was beamformed for the axial velocity estimation and two dedicated lines were beamformed for each of the two transverse velocity estimates. In total five unique beamformed lines were used to estimate the 3-D velocity vector for each flow line. Due to the asymmetric geometry of the transducer, two different transverse wavelengths $\lambda_{x}$ and $\lambda_{y}$ where used for the velocity estimator. The applied transverse wavelengths were $\lambda_{x}=3.42 \mathrm{~mm}$ and $\lambda_{y}=3.90 \mathrm{~mm}$ for the experimental setup and $\lambda_{x}=1.98 \mathrm{~mm}$ and $\lambda_{y}=2.18 \mathrm{~mm}$ for the in vivo measurements at the depth of $2.7 \mathrm{~cm}$ and $1.5 \mathrm{~cm}$ respective. For a more extensive description of the employed 3-D TO method, see previous work [13],[7],[8]. Echo cancellation of the beamformed data was subsequently perfomed with a low frequency Doppler filter algorithm [14]. 
TABLE I. TRANSDUCER AND EMISSIONS SEQUENCE SETUP

\begin{tabular}{|c|c|c|c|c|}
\hline \multicolumn{2}{|c|}{ Transducer } & \multicolumn{3}{|l|}{ Flow Parameters } \\
\hline Parameter & Value & Parameter & Phantom & In vivo \\
\hline Trandsucer type & 2-D phased array & Excitation signal & 8 cycles $\mathrm{Ha}$ & ing weighted \\
\hline No. of elements in $x$ & 35 ( 3 inactive rows) & Frequency & $3.0 \mathrm{MHz}$ & $3.0 \mathrm{MHz}$ \\
\hline No. of elements in y & 32 & Number of flow lines $F_{N}$ & 11 & 5 \\
\hline Pitch in $\mathrm{x}$ and $\mathrm{y}$ & $0.3 \mathrm{~mm}$ & $f_{p r f}$ & $7.5 \mathrm{kHz}$ & $12.6 \mathrm{kHz}$ \\
\hline Height & $0.278 \mathrm{~mm}$ & Steering angles & {$\left[-12^{\circ}: 12^{\circ}\right]$} & {$\left[-10^{\circ}: 10^{\circ}\right]$} \\
\hline Kerf & $0.022 \mathrm{~mm}$ & $\Delta$ line separation & $2.4^{\circ}$ & $5^{\circ}$ \\
\hline Sampling frequency & $70 \mathrm{MHz}$ & Receive apodization & Rect & Rect \\
\hline Decimation factor & 2 & No. of elements between TO apodization peaks & 24 & 24 \\
\hline Center frequency & $3.5 \mathrm{MHz}$ & No. of elements in TO apodization & 8 & 8 \\
\hline
\end{tabular}

\section{RESULTS}

In this section, results from the two conducted experiments are presented. First, results from the flow pump experiment are presented, and thereafter results from the in vivo experiment.

\section{A. Flow pump measurements}

From the experimental setup with the flow pump, four seconds of continuous data at $625 \mathrm{~Hz}$ was acquired corresponding to 4.8 cycles. Based on a B-mode image showing the crosssectional view of the vessel, a mask was manually drawn to segment out an area used for velocity estimates. Out-of-plane velocities were calculated in the selected area and the flow rate through it was estimated. The calculated flow rates are seen in Fig. 2. From the known cycle time of $0.84 \mathrm{~s}$, the data set was divided into four phase coherent cycles, and the mean and standard deviation (SD) were calculated. The average flow rate of the profile in Fig. 3 was $2.96 \pm 0.35 \mathrm{ml} / \mathrm{s}$ compared with the theoretical average flow rate of $3.06 \mathrm{ml} / \mathrm{s} \pm 0.09 \mathrm{ml} / \mathrm{s}$.

\section{$B$. In vivo measurements}

From the 3.07 seconds of continuous data obtained at $2.1 \mathrm{kHz}$, three complete heart cycles could be identified. As expected the highest peak velocities were found for the center flow line, which propagated closest to the center of the vessel. Peak out-of-plane velocites in each cycle were $83 \mathrm{~cm} / \mathrm{s}(\mathrm{t}=$ $0.69 \mathrm{~s}), 87 \mathrm{~cm} / \mathrm{s}$ and $90 \mathrm{~cm} / \mathrm{s}(\mathrm{t}=2.55 \mathrm{~s})$ based on an Mmode view. Based on the average time between these peak velocities, a heart cycle time of $0.93 \mathrm{~s}$ giving a heart rate of 64 beats/min was found. This heart cycle time was used in future calculations.

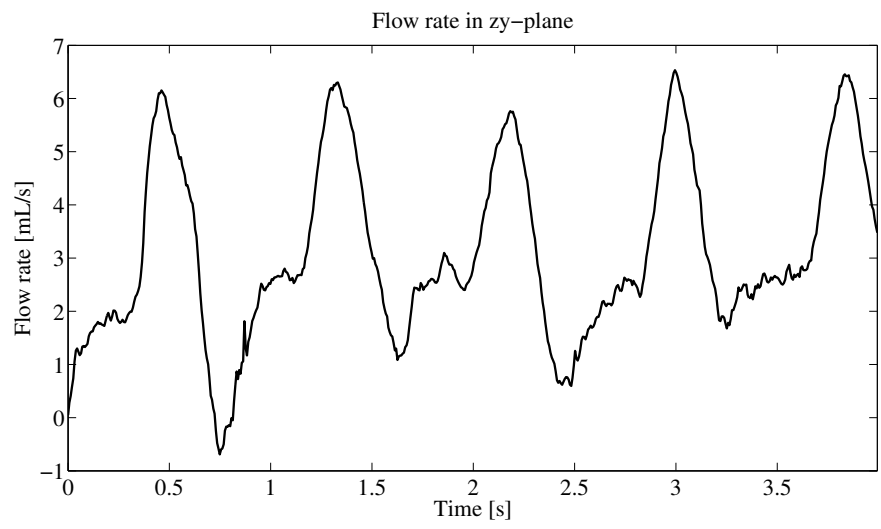

Fig. 2. Flow rates estimated from the out-of-plane velocity component in the experimental setup.

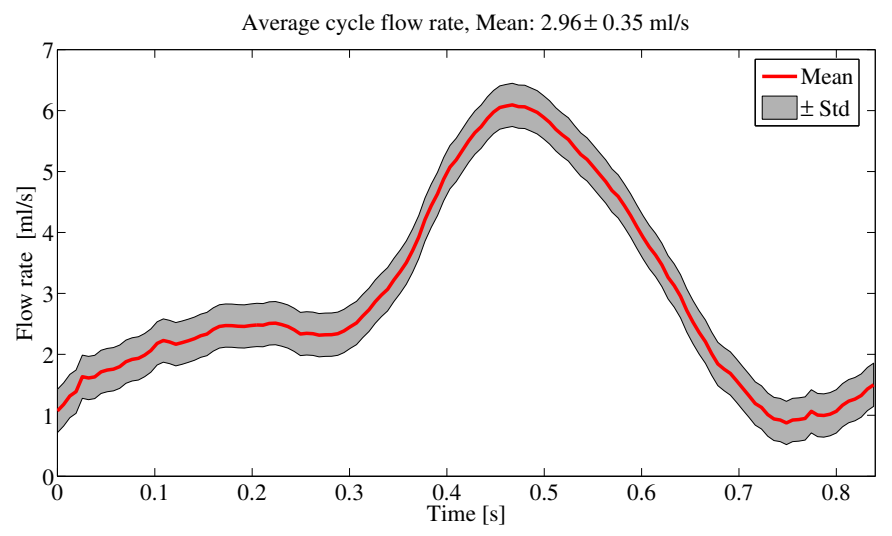

Fig. 3. Mean flow rate averaged over four complete cycles (red line) and one standard deviation (grey area). Mean average flow rate obtained in the phantom experiment was $2.96 \pm 0.35 \mathrm{ml} / \mathrm{s}$.

The discriminated velocity estimates for all three components were then scan converted and interpolated yielding a complete 3 -D vector velocity map at each time instance. The data set was divided into three subsets each of length 0.93 s. The mean 3-D vector velocities during one cycle was then found by calculating the average velocity estimate for all three velocity components across the three sub-samples. In Fig. 4 3 -D vector velocities averaged over three heart cycles at the identified end-diastole are presented. The magnitude of the velocity vector $|\mathbf{v}|=\sqrt{v_{x}^{2}+v_{y}^{2}+v_{z}^{2}}$ was found to be $17.0 \mathrm{~cm} / \mathrm{s}$ in the center of the vessel. The highest center velocity for $|\mathbf{v}|=$ $81.6 \mathrm{~cm} / \mathrm{s}$ was identified as the peak-systole. Spatial variance in peak velocity between each heart cycle and a slightly variance in the heart cycle time results in an average $|\mathbf{v}|$ during peak systole that is lower than the peak $v_{x}$ velocities during each of the three heart cycles. The 3-D vector velocity map is seen in Fig. 4. Based on the cross-sectional area and the out-of-plane velocity component, the estimated mean average flow rate was $257 \mathrm{ml} / \mathrm{min}$. In the literature the corresponding flow rate from the carotid artery found with spectral Doppler for a healthy person is $334 \mathrm{ml} / \mathrm{min}$ [16].

\section{Discussion \& CONCLUSION}

The presented results showed that $3-\mathrm{D}$ vector velocities at very high frame could be obtained when acquiring continuous data. In combination with the TO method, both the slow and fast flow could be detected in pulsating flow setups. The TO method was applicable for estimating accurate flow rates in an experimental setup with a flow pump generating a carotid flow profile. 


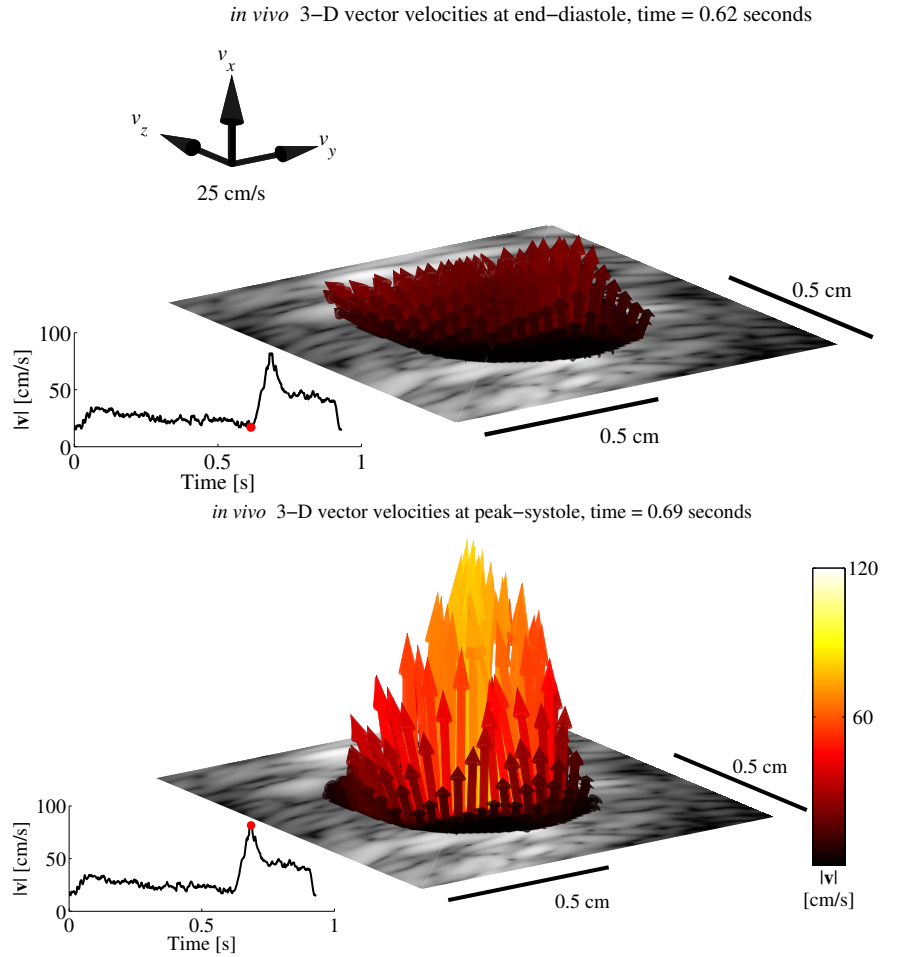

Fig. 4. 3-D vector velocities at the end-diastole, $|\mathbf{v}|=17.0 \mathrm{~cm} / \mathrm{s}$. 3-D vector velocities at the peak-systole, $|\mathbf{v}|=81.6 \mathrm{~cm} / \mathrm{s}$. 3-D vector velocities averaged over three complete and consecutive heart cycles. The bottom-left graph shows the magnitude of $\mathbf{v}$ in the center of the vessel at the time instance of the cycle indicated by the the red dot. The colored arrows depicts the direction of the flow and its magnitude. The velocity arrows are plotted on top of a B-mode image and only values within the discriminator are shown. Mean flow rate over the averaged cycle was $257 \mathrm{ml} / \mathrm{min}$.

The presented method offers a unique possibility to study complex flow pattern in 3-D, even when slow and fast flow is present. Furthermore, accurate angle-independent flow rates and peak velocity estimates can be derived from the 3-D vector flow. However, further validation of the method against e.g. similar MRI estimates are needed to clarify the accuracy and potential for clinical use.

\section{ACKNOWLEDGMENT}

This work was supported by grant 82-2012-4 from the Danish National Advanced Technology Foundation and by BK Ultrasound Aps.

\section{REFERENCES}

[1] D. H. Evans, J. A. Jensen, and M. B. Nielsen, "Ultrasonic colour Doppler imaging," Interface Focus, vol. 1, no. 4, pp. 490-502, 2011.
[2] L. N. Bohs and G. E. Trahey, "A novel method for angle independent ultrasonic imaging of blood flow and tissue motion," IEEE Trans. Biomed. Eng., vol. 38, pp. 280-286, 1991.

[3] J. A. Jensen and S. I. Nikolov, "Directional synthetic aperture flow imaging," IEEE Trans. Ultrason., Ferroelec., Freq. Contr., vol. 51, pp. 1107-1118, 2004.

[4] M. Tanter, J. Bercoff, L. Sandrin, and M. Fink, "Ultrafast compound imaging for 2-D motion vector estimation: application to transient elastography," IEEE Trans. Ultrason., Ferroelec., Freq. Contr., vol. 49, pp. 1363-1374, 2002.

[5] J. A. Jensen and P. Munk, "A new method for estimation of velocity vectors," IEEE Trans. Ultrason., Ferroelec., Freq. Contr., vol. 45, pp. 837-851, 1998.

[6] S. Holbek, M. Pihl, C. Ewertsen, M. Nielsen, and J. A. Jensen, "3-D velocity estimation for two planes in vivo," in Proc. IEEE Ultrason. Symp., 2014, pp. 1706-1709.

[7] M. J. Pihl and J. A. Jensen, "A transverse oscillation approach for estimation of three-dimensional velocity vectors. Part I: Concept and simulation study," IEEE Trans. Ultrason., Ferroelec., Freq. Contr., vol. 61, pp. 1599-1607, 2014.

[8] M. J. Pihl, M. B. Stuart, B. G. Tomov, M. F. Rasmussen, and J. A. Jensen, "A transverse oscillation approach for estimation of threedimensional velocity vectors. Part II: Experimental validation," IEEE Trans. Ultrason., Ferroelec., Freq. Contr., vol. 51, no. 10, pp. 16081618, 2014.

[9] J. Provost, C. Papadacci, J. E. Arango, M. Imbault, M. Fink, J. L. Gennisson, M. Tanter, and M. Pernot, "3-D ultrafast ultrasound imaging in vivo," Physics in Medicine and Biology, vol. 59, no. 19, pp. L1-L13, 2014.

[10] J. A. Jensen, "A new estimator for vector velocity estimation," IEEE Trans. Ultrason., Ferroelec., Freq. Contr., vol. 48, no. 4, pp. 886-894, 2001.

[11] J. A. Jensen, H. Holten-Lund, R. T. Nilsson, M. Hansen, U. D. Larsen, R. P. Domsten, B. G. Tomov, M. B. Stuart, S. I. Nikolov, M. J. Pihl, Y. Du, J. H. Rasmussen, and M. F. Rasmussen, "SARUS: A synthetic aperture real-time ultrasound system," IEEE Trans. Ultrason., Ferroelec., Freq. Contr., vol. 60, no. 9, pp. 1838-1852, 2013.

[12] J. M. Hansen, M. C. Hemmsen, and J. A. Jensen, "An object-oriented multi-threaded software beamformation toolbox," in Proc. SPIE Med. Imag., vol. 7968, March 2011, pp. 79680 Y 1-9.

[13] M. J. Pihl and J. A. Jensen, "3D velocity estimation using a 2D phased array," in Proc. IEEE Ultrason. Symp., 2011, pp. 430-433.

[14] A. P. G. Hoeks, J. J. W. van de Vorst, A. Dabekaussen, P. J. Brands, and R. S. Reneman, "An efficient algorithm to remove low frequency Doppler signal in digital Doppler systems," Ultrason. Imaging, vol. 13, pp. 135-145, 1991.

[15] C. Kasai, K. Namekawa, A. Koyano, and R. Omoto, "Real-Time TwoDimensional Blood Flow Imaging using an Autocorrelation Technique," IEEE Trans. Son. Ultrason., vol. 32, pp. 458-463, 1985.

[16] P. Likittanasombut, P. Reynolds, D. Meads, and C. Tegeler, "Volume flow rate of common carotid artery measured by Doppler method and color velocity imaging quantification (CVI-Q)," Journal of Neuroimaging, vol. 16, no. 1, pp. 34-38, 2006. 